\title{
Sensitivity of historical orographically enhanced extreme precipitation events to idealized temperature perturbations
}

\author{
Mari Ingeborg Sandvik ${ }^{1,2} \cdot$ Asgeir Sorteberg $^{1,2} \cdot$ Roy Rasmussen $^{3}$
}

Received: 5 July 2016 / Accepted: 20 February 2017 / Published online: 3 March 2017

(C) The Author(s) 2017. This article is published with open access at Springerlink.com

\begin{abstract}
Using high resolution convective permitting simulations, we have investigated the sensitivity of historical orographically enhanced extreme precipitation events to idealized temperature perturbations. Our simulations were typical autumn and winter synoptic scale extreme precipitation events on the west coast of Norway. The response in daily mean precipitation was around $5 \% / \mathrm{K}$ for a $2{ }^{\circ} \mathrm{C}$ temperature perturbation with a clear topographical pattern. Low lying coastal regions experienced relative changes that were only about $1 / 3$ of the changes at higher elevations. The largest changes were seen in the highest elevations of the near coastal mountain regions where the change was in order of $+7.5 \% / \mathrm{K}$. With a response around $5 \% / \mathrm{K}$, our simulations had a precipitation response that was around $2 \% / \mathrm{K}$ lower than Clausius-Clapeyron scaling and $3 \% / \mathrm{K}$ lower than the water vapor change. The below ClausiusClapeyron scaling in precipitation could not be explained by changes in vertical velocities, stability or relative humidity. We suggest that the lower response in precipitation is a result of a shift from the more efficient ice-phase precipitation growth to less effective rain production in a warmer atmosphere. A considerable change in precipitation phase was seen with a mean increase in rainfall of $16 \% / \mathrm{K}$ which was partly compensated by a reduction in snowfall
\end{abstract}

Mari Ingeborg Sandvik

mari.sandvik@uib.no

1 Geophysical Institute, University of Bergen, 5020 Bergen, Norway

2 Bjerknes Center for Climate Research, University of Bergen, Bergen, Norway

3 Research Applications Laboratory, National Center for Atmospheric Research, Boulder, USA of around $23 \% / \mathrm{K}$. This change may have serious implications for flooding and geohazards.

Keywords Extreme precipitation - Climate sensitivity experiments $\cdot$ Regional modeling $\cdot \mathrm{WRF} \cdot$ Norway

\section{Introduction}

Extreme precipitation in Norway is associated with the onshore flow of a moist jet of air over the complex terrain of southern Norway. This large moisture flow occurs in association with extratropical cyclones located in the North Atlantic. It is of great interest to understand how this atmospheric river and the associated extreme orographic precipitation may change in the future as this moisture source results in a large fraction of annual precipitation over the Norwegian mountains important to hydropower and recreation. In addition, the high precipitation rates associated with this flow often leads to adverse conditions for transportation and avalanche occurrence.

In a warming climate available moisture will generally increase, roughly following the atmospheric saturation specific humidity (O'Gorman and Schneider 2009b; O'Gorman and Muller 2010). The Clausius-Clapeyron (CC) relation is often used as a rule of thumb on how extreme precipitation may change in a warmer climate (e.g. Allan and Ingram 2002; Trenberth et al. 2003; Pall et al. 2006; Loriaux et al. 2013). By using a simple numerical model for idealized extreme storms, Siler and Roe (2014) found that orographic precipitation had a lower response to surface warming than expected by the CC-relation. They noted a decrease in the condensation rate combined with an increase in transport of precipitation to the lee side of the mountain, where evaporation occurs, as the main reasons 
for the lower response in precipitation. On the other hand, Rasmussen et al. (2011) found a higher response than the CC-relation in a warmer climate for accumulated winter precipitation for some months in high-precipitation years over the Colorado Headwaters $(\mathrm{CH})$ region. The two main factors for the increase were an increase in precipitation efficiency, due to higher fall speed for rain than snow as the system passes the barrier; and an increase in riming growth, due to the increased cloud water mixing ratio. At temperatures below 295 K Singh and O'Gorman (2014) found the rate of increase in precipitation to be sensitive to the fall speed of hydrometeors, in agreement to that found by Rasmussen et al. (2011). Liu et al. (2016) also found a higher response for winter precipitation than the CC-relation for future climate over the continental western United States and Canada.

Changes in the atmospheric lapse rate and vertical velocity can also result in deviations from the $\mathrm{CC}$ relation for precipitation extremes (O'Gorman and Schneider 2009a; Trenberth et al. 2003; Sugiyama et al. 2010). An example of this is latent heat release due to condensation. Latent heat release changes the stability in the atmosphere, making it more stable. The same latent heat release can increase the updraft velocity (Sørland et al. 2016). Using a cloudresolving model, Muller and O'Gorman (2011) found that changes in vertical velocities tended to weaken the strength of precipitation extremes despite an increase of upper tropospheric updraft velocities for mixed phased clouds in the tropics.

A number of climate model simulations show a poleward or eastward shift of the mid-latitude storm tracks (Bengtsson et al. 2006; Yin 2005). However, the climate model trajectories of storm tracks are highly variable for different ensemble members (Bengtsson et al. 2006; Ulbrich et al. 2008; Laîné et al. 2009), and knowing which one will represent reality in the future is difficult. Climate models do however agree on a warmer and moister climate for mid and high latitudes (Collins et al. 2013).

An idealized method for analyzing the sensitivity of extreme events to temperature changes is the use of the pseudo global warming method [PGW, also called surrogated climate change (SCC) method]. PGW can be used to perform idealized experiments to better understand how sensitive regional weather is to certain aspects of a warming climate. In PGW experiments a climate change signal is introduced to the initial and boundary conditions. Several PGW experiments have focused on Europe with a climate change signal added to the temperature field as well as the atmospheric water vapor content (e.g. Schär et al. 1996; Frei et al. 1998; Im et al. 2009; Kröner et al. 2016). The PGW method is conducted by introducing a temperature anomaly in the air, land, and sea surface to the initial and lateral boundary conditions. The temperature anomaly may be a uniform change, a change in vertical profile, or obtained from a GCM or RCM. Since the specific humidity have the tendency to follow the CC-relation, the RH is often chosen to be kept constant. Schär et al. (1996) showed that this procedure does not affect the dynamical structure (gradients and location of the synoptic systems) entering the model on the lateral boundaries. The assumption of a constant RH is an idealization compared to the real world. However, by using observations, Bony et al. (1995) found only small variations in RH. The PGW methods are idealized experiments in that they isolate the effects of increased temperature and specific moisture content. Kröner et al. (2016) separated the climate change signals into thermodynamic, lapse-rate and circulation effects with the use of the PGW method for a temperature perturbation that was vertically dependent. They showed that for summertime mean precipitation over Scandinavia the changes were mainly attributed to the thermodynamic effect associated with a vertically uniform warming and changes in the circulation, and to a lesser extent the effect of changes in warming with height.

In this study, we will use the PGW method presented in Schär et al. (1996) to study how orographically enhanced precipitation extremes over the west coast of Norway change with temperature. How these extremes change as a result of changes to the large scale is beyond the scope of this study. Rather, we focus on the impact of thermodynamic changes to these phenomena. In particular, we will focus on:

1. How much do orographically enhanced stratiform precipitation extremes change with temperature?

2. Whether the chosen extreme events follow the CC-relation and if not, what are the causes of the deviations?

\section{Data and methods}

\subsection{Study area}

The southern part of Norway is divided meridionally by the Langfjella mountain range (Fig. 1). The south western part has complex topography with deep and narrow valleys, fjords, and mountains reaching up to $2000 \mathrm{~m}$. This region experiences large amounts of precipitation, typically exceeding $2000 \mathrm{~mm} /$ year (Heikkilä et al. 2011). The orographic complexity causes large variability in the observed precipitation amount over relatively short distances. Most of the extreme precipitation events in this area are a result of orographically enhanced precipitation from fronts embedded in North Atlantic mature low-pressure systems. They often occur during fall and winter months when the low-pressure systems become more frequent and intense 
Fig. 1 The WRF model $2 \times 2 \mathrm{~km}$ resolution domain and topography. The main north-south mountain range is the Langfjella having peaks up to $2000 \mathrm{~m}$. The black box over Norway represents where the influx and outflux of humidity were calculated to give an estimate of the drying ratio

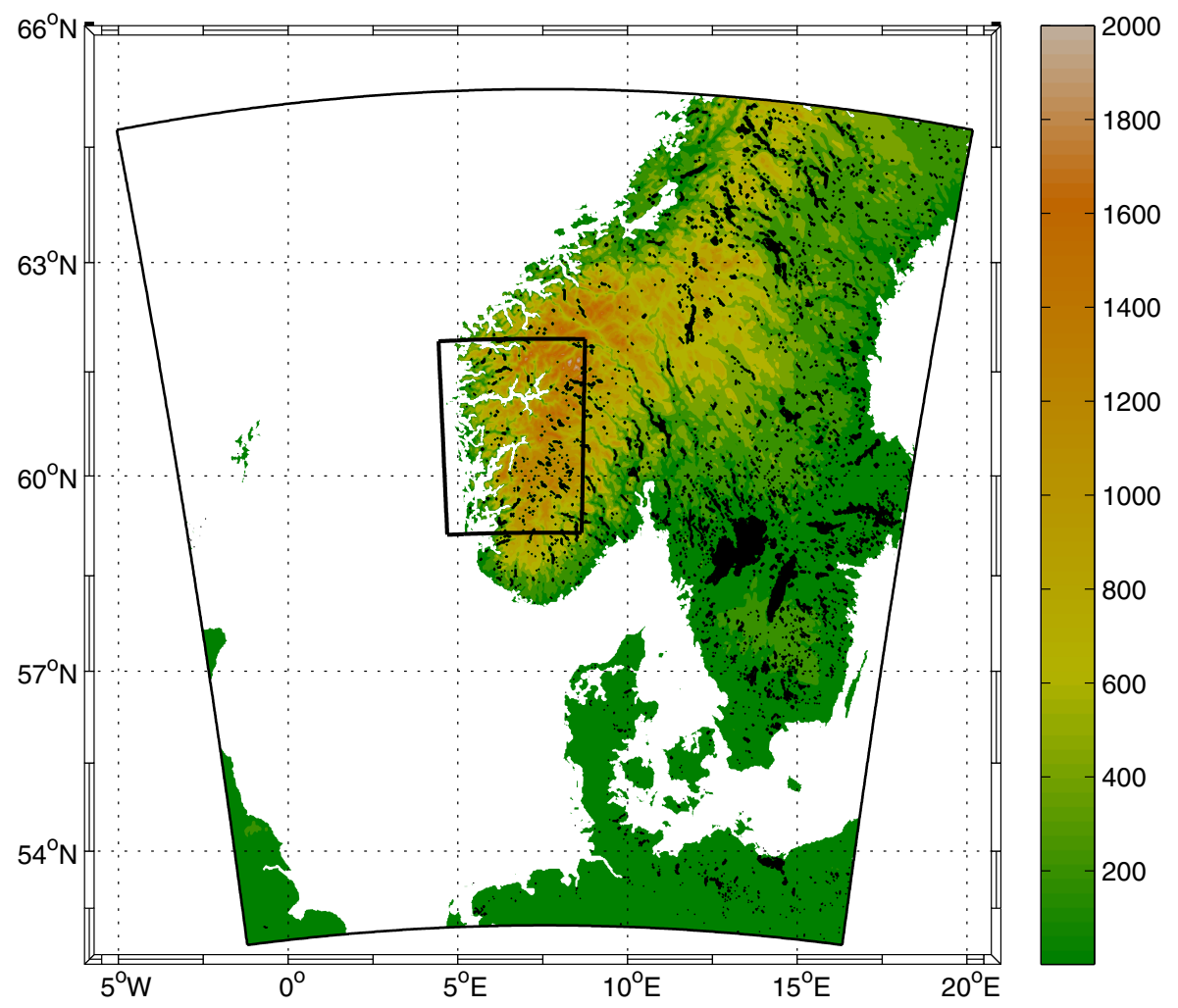

conditions for the model simulations are available for this period. This resulted in the 11 events listed in Table 1.

\subsection{Model setup}

To examine the impact of thermodynamic climate change on extreme precipitation over Western Norway, simulations with and without climate change impacts on temperature and moisture were performed with the Advanced Research WRF (ARW) model (version WRF3.6.1). WRF is a fully compressible nonhydrostatic model, with a terrain-following hydrostatic pressure vertical coordinate system (Skamarock et al. 2008). Table 2 lists the model setup and physics options used in these simulations. The model domain contains $600 \times 700$ grid points with a $2 \times 2 \mathrm{~km}$ horizontal resolution, which covers Southern Norway, parts of the United Kingdom, Sweden and Denmark as well as the Norwegian Sea, North Sea and Skagerrak (Fig. 1). Due to the high spatial resolution, convection is mostly resolved by the model, and thus the convection scheme was turned off. The atmosphere is divided into 51 vertical (eta) model levels. The model top is located at $50 \mathrm{hPa}$ with no vertical damping layer at the top. Six hourly ERA-INTERIM reanalysis (Dee et al. 2011) from the European Center for Medium Range Weather Forecast (ECMWF) were used as initial and lateral boundary conditions.

The domain is a compromise between two factors. It has to be big enough to allow weather systems to develop occurred from 1990 onwards, since good quality boundary 


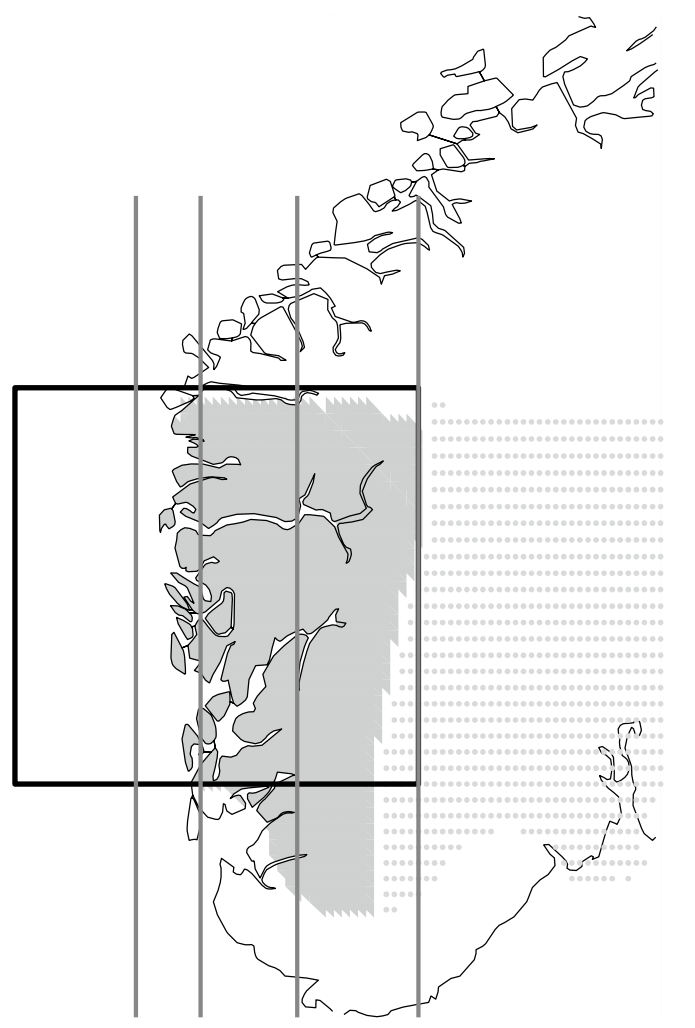

Fig. 2 The grey shaded areas represent the WC area. The grey dots on the other hand indicate the leeside of the mountain range called Southern Norway (SN, region 2 in the MET Norway classification), which is used to calculate the fraction of precipitation that falls within the WC area. The black square indicates the area used to calculate the vertical transects. The dark grey lines indicate the $4.5^{\circ}, 5.3^{\circ}, 6.5^{\circ}$ and $8^{\circ}$ longitude lines, respectively

Table 1 The dates of the 11 extreme precipitation events are listed in the first column their own orographically induced dynamics (which often includes an orographically induced high pressure anomaly off the west coast of Norway), but still constrained by the synoptic scale flow through the lateral boundary conditions. Larger domains were tested, which resulted in a degradation of the daily precipitation compared to observations, as well as changes in the tracks of the synoptic systems when temperature perturbations were imposed. To reduce this drift in the large scale flow, we tested one-way nesting by introducing a $10 \mathrm{~km}$ resolution outer domain that covered parts of North America, the north Atlantic and Europe that was spectrally nudged. We found that the introduction of a spectrally nudged outer domain did not produce significant improvements compared to the single high resolution domain simulations. The nudging had to be applied down to wavelengths within the mesoscale range to constrain the large-scale flow, and this may have influenced the model's ability to produce the orographically induced dynamics. Thus, a single high resolution domain without nudging is used in this study.

Each model simulation was $72 \mathrm{~h}$ long, starting with an $18 \mathrm{~h}$ spin up period prior to the extreme precipitation event. The spin up time allows the model to equilibrate to the initial conditions and to start the production of precipitation. Both longer and slightly shorter spin up times were tested with no discernable differences in the accumulated daily precipitation during the extreme event.

\begin{tabular}{lllllr}
\hline Date, ddmmyyyy & $\begin{array}{l}\text { Percentage of } \\
\text { stations [\%] }\end{array}$ & $\begin{array}{l}\text { Max precipitation } \\
\text { [mm/day] }\end{array}$ & $\begin{array}{l}\text { Number of } \\
\text { stations }\end{array}$ & MAE [mm/day] & ME [\%] \\
\hline 05031990 & 60 & 109.4 & 127 & 15.0 & -16.7 \\
11011992 & 74 & 206.0 & 128 & 29.6 & 3.1 \\
19101995 & 61 & 121.2 & 115 & 18.6 & -15.0 \\
27101995 & 67 & 184.6 & 115 & 17.3 & -16.9 \\
02031997 & 94 & 175.0 & 113 & 31.0 & -8.2 \\
04021999 & 65 & 140.6 & 111 & 14.1 & -3.6 \\
29111999 & 65 & 135.8 & 113 & 21.5 & 1.8 \\
15112004 & 79 & 195.0 & 98 & 24.5 & -14.0 \\
14092005 & 85 & 179.5 & 93 & 21.0 & -4.1 \\
15112005 & 85 & 223.0 & 95 & 23.7 & 2.9 \\
12012009 & 83 & 123.5 & 89 & 27.4 & 9.5 \\
Mean & 74 & 163.1 & 109 & 22.2 & -5.6 \\
\hline
\end{tabular}

Dates indicated are end dates for the $24 \mathrm{~h}$ observed precipitation (06-06 UTC). Thus the bulk of the precipitation occurred the day before. The second column states the percentage of the 20 stations that has data back to 1900 that observed extreme precipitation during a given event. The maximum daily accumulated precipitation that was recorded (using all stations having data for the event) during the given events is found in the third column. Mean absolute error (MAE) and mean error (ME) are listed in the two last columns, respectively. The number of observational stations that have been used to validate the control runs (CTR) when calculating MAE and ME is listed is the fourth column 
Table 2 Model setup

\begin{tabular}{ll}
\hline Model version & WRF (ARW) version 3.6.1 \\
\hline Duration & 3d run, 24 analyze period $(19 \mathrm{~h}$ after start $)$ \\
& Output frequency of $1 \mathrm{~h}$ \\
Grid & $2 \mathrm{~km}$ grid spacing \\
& $600 \times 700$ grid points $(\mathrm{EW} \times \mathrm{NS})$ \\
& 51 vertical levels \\
Physics & Thompson microphysics scheme \\
& Yonsei University PBL scheme \\
& Unified Noah land surface model \\
& Radiation: RRTMG longwave and shortwave scheme \\
& No convection scheme \\
\hline
\end{tabular}

\subsection{PGW-simulations}

For the sensitivity experiments we follow the PGW method outlined in the introduction. An idealized uniform $\pm 2{ }^{\circ} \mathrm{C}$ perturbation of all the temperature-fields in the atmosphere, the land surface and the sea surface was imposed on the initial and lateral boundary conditions. Relative humidity was kept constant, resulting in an adjustment of the specific humidity according to the CC-relation. The surface pressure was recalculated after introducing the temperature perturbation. This adjustment as well as the new temperature fields resulted in a hydrostatic adjustment of the geopotential height, $\Phi_{\Delta T}$ :

$\Phi_{\Delta T(p)}=\int_{p}^{p_{s, \Delta T}} R(T+\Delta T) \frac{d p}{p}$

where $\mathrm{p}$ is at some reference pressure level. The modification of the geopotential height ensures that it is dynamically consistent with the temperature fields. This is especially important over high topography where pressure surfaces can be shifted upward with increased temperature. In the following, the control runs and sensitivity simulations will be indicated as $\mathrm{CTR}, 2 \mathrm{PL}\left(+2{ }^{\circ} \mathrm{C}\right.$ perturbation) and $2 \mathrm{NG}$ $\left(-2{ }^{\circ} \mathrm{C}\right.$ perturbation), respectively.

\section{Results}

In the following, a $24 \mathrm{~h}$ analysis period is chosen from 6 UTC to 6 UTC.

To provide a general picture of how sensitive these types of extreme precipitation events are to a warmer/ colder climate, the 11 cases were composited and analyzed. The magnitude of the $2 \mathrm{PL}$ and $2 \mathrm{NG}$ simulations experienced a similar response, but in opposite directions. Therefore, figures and numbers presenting the sensitivity will be from the warmer climate response. To quantify the amount of variation between the 11 cases one standard deviation is given after each value (indicated by \pm ) given in this section.

\subsection{Synoptic situations}

Six hourly ERA-Interim reanalysis data (Dee et al. 2011) for mean sea level pressure (MSLP) and temperature at $850 \mathrm{hPa}$ is used to evaluate the synoptic systems connected with these extremes. The synoptic situation for each of the extreme events is not identical. They are however similar in that they all have a pressure dipole where a low-pressure system in the north (typically in the Nordic Seas ${ }^{1}$ ) is combined with a high-pressure system in the south (typically over central Europe) forcing a mix of cold arctic air with warm humid air from the south toward the west coast of Norway (Fig. 3). From an analysis of the synoptic weather patterns corresponding with extreme precipitation events for the WC region, the "04021999" case shown in Fig. 3 visualize a common synoptic situation for these events. The prevailing synoptic flow hitting the west coast of Norway is in over half of the cases southwesterly flow while the rest either has westerly or northwesterly flow. Large temperature gradients associated with frontal systems in connection with the low can be found in some of the cases (Fig. 3). The passing of these frontal systems results in the large observed precipitation amounts in the WC region. A more detailed analysis of the synoptic situations leading to extreme precipitation on the Norwegian West coast can be found in Heikkilä and Sorteberg (2012).

\subsection{Model validation}

Evaluation of the CTR simulations is performed by comparing the daily-accumulated precipitation from WRF against the daily-accumulated precipitation observations collected by MET Norway. The WRF nearest gridpoint to

\footnotetext{
1 The Nordic Seas is a common name for The Norwegian Sea, The Iceland Sea, The Greenland Sea, The Barents Sea and The North Sea.
} 
Fig. 3 The synoptic situation for February 3rd 1999 at 6 UTC. The darker thin grey lines show the mean sea level pressure (MSLP) and the colored shading represent the temperature at $850 \mathrm{hPa}$. The red circle represents the lowest pressure measured in the area. The landmasses are shown with the lighter thick lines

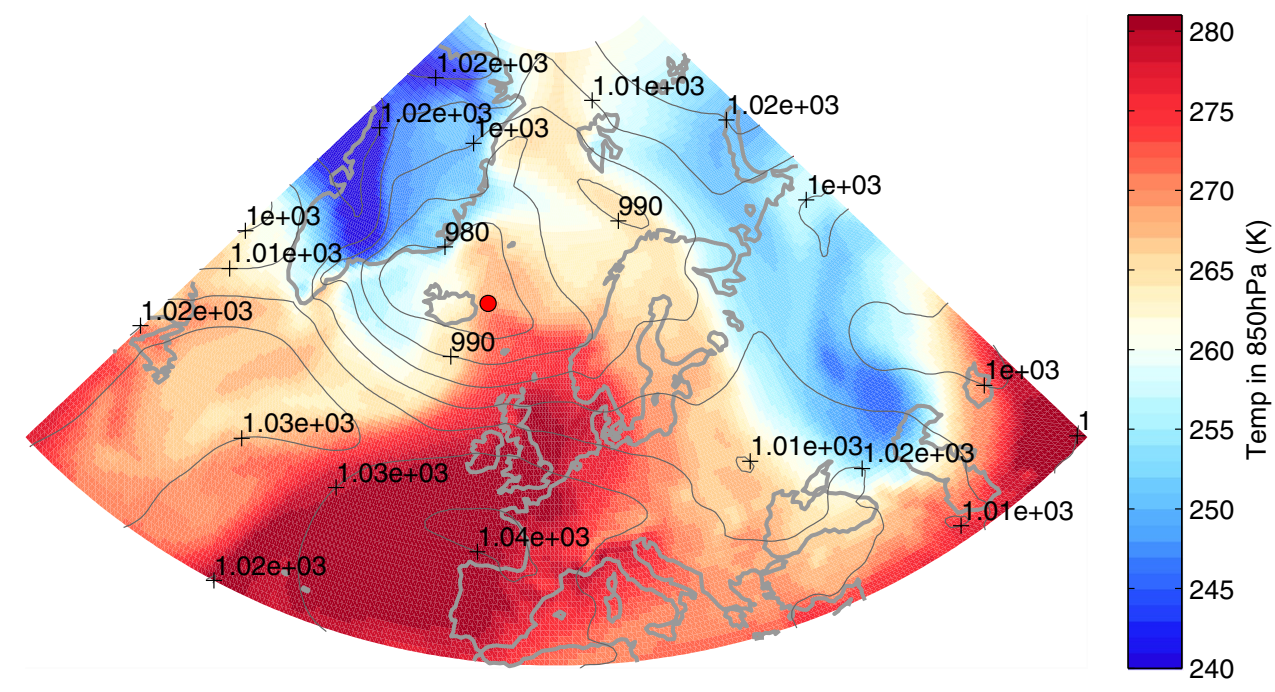

(a)

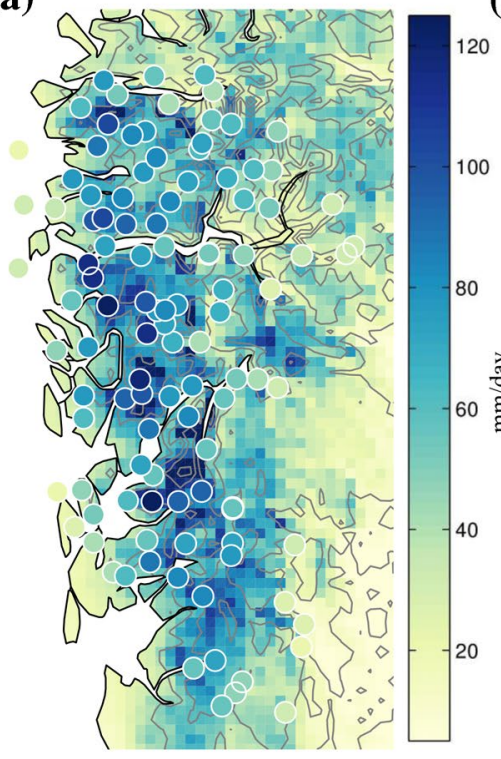

(b)

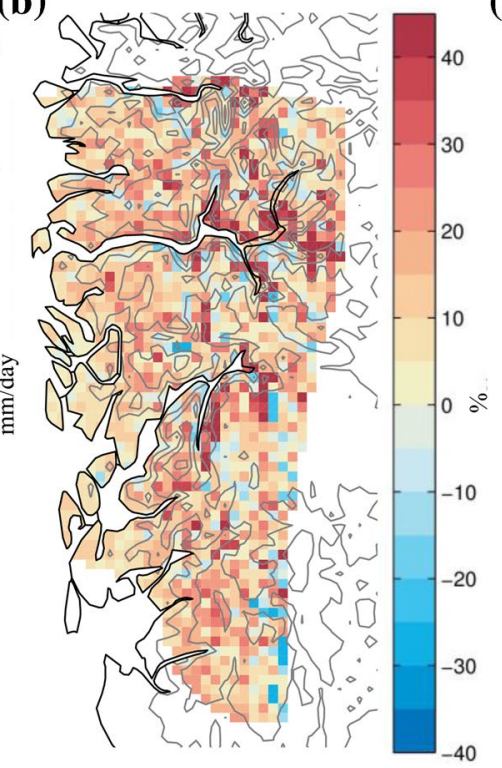

(c)

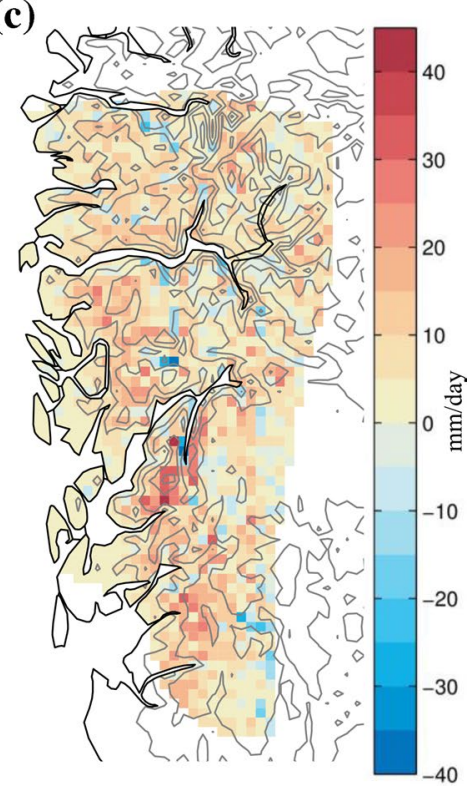

Fig. 4 a Average of daily (06-06 UTC) precipitation ( $\mathrm{mm} /$ day) in the control simulation (CTR) for the 11 selected extreme precipitation cases. The circles represent the observations for the same cases. b, c Percentage [\%] and absolute change [ $\mathrm{mm} /$ day], respectively, for the
$+2{ }^{\circ} \mathrm{C}$ perturbation simulations (2PL) compared to the control (CTR) over the West Coast area. The topography is indicated by the grey contours with a $200 \mathrm{~m}$ contour interval

locations, but it should be kept in mind that the observations are probably biased low for snowfall (high elevations). The observational stations within the WC area are used to calculate the Mean Absolute Error (MAE) and the Mean Error/Bias (ME), see Table 1. On average WRF is underestimating the daily precipitation by $5.6 \pm 9.2 \%$ with a MAE of $22.2 \pm 5.7 \mathrm{~mm} /$ day. The average mean daily-accumulated precipitation in WRF and the observations of the 11 cases can be viewed in Fig. 4a. From Fig. 4a it appears that WRF is able to reasonably reproduce the observed 
Table 3 mean absolute error (MAE) and mean error (ME) for different elevation intervals and distance to the coast

\begin{tabular}{llll}
\hline Region & Elevation & MAE [mm/day] & ME [\%] \\
\hline Coastal & $\mathrm{h}<30$ & 12.8 & -19.5 \\
& $30 \leq \mathrm{h}<100$ & - & - \\
& $100 \leq \mathrm{h}<350$ & 18.1 & -18.3 \\
& $\mathrm{~h} \geq 350$ & - & - \\
Near costal & $\mathrm{All}$ & 13.3 & -19.4 \\
& $\mathrm{~h}<30$ & 23.5 & -7.7 \\
& $30 \leq \mathrm{h}<100$ & 21.6 & -23.7 \\
& $100 \leq \mathrm{h}<350$ & 22.6 & -11.3 \\
& $\mathrm{~h} \geq 350$ & 20.0 & -11.1 \\
& $\mathrm{All}$ & 22.2 & -15.0 \\
Inland & $\mathrm{h}<30$ & 23.8 & 50.8 \\
& $30 \leq \mathrm{h}<100$ & 39.9 & 45.2 \\
& $100 \leq \mathrm{h}<350$ & 20.9 & -2.0 \\
& $\mathrm{~h} \geq 350$ & 16.1 & 10.5 \\
& $\mathrm{All}$ & 22.6 & 19.0 \\
\hline
\end{tabular}

The Coastal, Near Coastal and Inland regions are defined in Sect. 3.2 and can be seen in Fig. 2. The height intervals of the stations are created to give more or less an even number of observational stations within each interval ( 28 stations) when calculating MAE and ME

pattern; the lowest precipitation amounts are located along the coast, the largest precipitation amounts are located where the airflow first hits the major slope in the topography; further inland precipitation values are in the 60 to $80 \mathrm{~mm} /$ day range.

Stations containing data for at least 6 of the 11 cases (109 stations) were divided into topographic height intervals (Table 3) and distance to the ocean (Fig. 2). From this we are able to evaluate where WRF is underestimating and overestimating the observed precipitation (Table 3). Coastal, Near Coastal and Inland areas are defined as the area between $4.5^{\circ}$ and $5.3^{\circ}$ longitude, $5.3^{\circ}$ and $6.5^{\circ}$ longitude, and $6.5^{\circ}$ and $8^{\circ}$ longitude, respectively (dark grey lines in Fig. 2). The inland area experienced a general overestimation of precipitation except for a weak underestimation of $2 \%$ for elevations located between 100 and $350 \mathrm{~m}$ a.s.l. One should keep in mind that the observational undercatch in inland high elevation areas could be considerable and may explain parts of the overestimation by WRF. For the other categories a general underestimation is present. The largest mean underestimations are found at the stations in the coastal area and at elevations between 30 and $100 \mathrm{~m}$ a.s.l. for the near coastal area. In other words, WRF has a tendency to not produce enough precipitation in the coastal areas and near coastal areas, but rather deposit it further inland.

To be sure that the differences in precipitation are not a result of a time shift in the precipitation, the onset of the accumulated precipitation was checked for all cases. No shift in the onset were detected that could have altered the results.

\subsection{Sensitivity to temperature perturbations}

In this section we examine the response of the meteorological variables that are relevant for understanding the changes in precipitation to the imposed change in temperature fields, by comparing two PGW simulations with CTR, one with a positive temperature perturbation $\left[2 \mathrm{PL}\left(+2^{\circ} \mathrm{C}\right)\right]$ and one with a negative perturbation $\left[2 \mathrm{NG}\left(-2^{\circ} \mathrm{C}\right)\right]$.

Since we are mainly interested in changes in the parts of the atmosphere that have the bulk of the water vapor, all column integrated variables are weighted by the amount of water vapor (weight $_{i}=\frac{q_{i} \rho_{i} z_{i}}{\sum_{i=1}^{N} q_{i} \rho_{i} z_{i}}$, where $q_{i}$ is specific humidity, $\rho_{i}$ is the averaged density of the air within each layer, $z_{i}$ is the depth of each layer, and $\mathrm{N}$ is the number of layers). All changes are scaled with the initial temperature perturbation.

\subsubsection{Area averaged response}

Two-meter temperature was used to quantify the CC relation. When averaging the WC region for the 11 cases the temperature change had an average value of $7 \% / \mathrm{K}$, consistent with CC expectations. In high elevation areas, the coldest temperatures and the highest values of the CC-relation was found with a maximum of $7.5 \%$. The warmest temperatures and lowest values of the CC-relation with a minimum value of $6.7 \% / \mathrm{K}$ was found in the coastal region. The area and column average change in specific humidity over the WC region for the 11 cases experienced a larger change than the CC-relation imposed on the boundary conditions with an average of $8.1 \pm 0.4 \% / \mathrm{K}$ for increased temperature (Table 6). The change is uniform throughout the region.

The area average change in the extreme precipitation over the WC region is on average $5.2 \pm 0.9 \% / \mathrm{K}$ for the warmer simulations (Table 4). The height intervals were chosen to evenly distribute the number of gridpoints within each height interval ( $\sim 50$ gridpoints). The largest percentage increases are located in high elevation areas where the change was around $6.4 \% / \mathrm{K}$ (for elevations higher than $650 \mathrm{~m}$ a.s.1.) compared to around $2.3 \% / \mathrm{K}$ for low elevation areas (elevations lower than $150 \mathrm{~m}$ a.s.1.) (Fig. 5). The increased relative sensitivity in high elevation areas may be a result of the larger fractional change in condensation with lower temperatures as a result of the temperature dependence of CC's equation (Siler and Roe 2014). Regionally there are large percentage increases along the fjords located in areas of relative steep topography in the inland area with values above $15 \% / \mathrm{K}$ (Fig. $4 \mathrm{~b}$ ). Even if the relative change is largest along the fjords and in high topography, the largest 
Table 4 Accumulated daily precipitation, rain, and snow plus graupel amounts (CTR columns) for each of 11 extreme events and the mean

\begin{tabular}{|c|c|c|c|c|c|c|c|c|c|}
\hline \multirow{3}{*}{$\begin{array}{l}\text { Date } \\
\text { ddmmyyyy }\end{array}$} & \multicolumn{3}{|c|}{ Precipitation } & \multicolumn{3}{|l|}{ Rain } & \multicolumn{3}{|c|}{ Snow and Graupel } \\
\hline & \multirow{2}{*}{$\begin{array}{l}\mathrm{mm} / \text { day } \\
\text { CTR }\end{array}$} & \multicolumn{2}{|l|}{$\%$} & \multirow{2}{*}{$\begin{array}{l}\mathrm{mm} / \text { day } \\
\text { CTR }\end{array}$} & \multicolumn{2}{|l|}{$\%$} & \multirow{2}{*}{$\begin{array}{l}\mathrm{mm} / \text { day } \\
\text { CTR }\end{array}$} & \multicolumn{2}{|l|}{$\%$} \\
\hline & & $2 \mathrm{PL}$ & $2 \mathrm{NG}$ & & $2 \mathrm{PL}$ & $2 \mathrm{NG}$ & & $2 \mathrm{PL}$ & $2 \mathrm{NG}$ \\
\hline 05031990 & 36.6 & 8.6 & -9.0 & 9.2 & 85.8 & -55.6 & 27.5 & -17.1 & 6.5 \\
\hline 11011992 & 53.7 & 12.2 & -10.0 & 30.0 & 56.4 & -46.6 & 23.7 & -44.8 & 35.2 \\
\hline 19101995 & 40.6 & 7.9 & -8.3 & 36.6 & 16.3 & -27.6 & 4.0 & -72.3 & 165.5 \\
\hline 27101995 & 51.2 & 14.4 & -11.7 & 47.8 & 20.7 & -21.8 & 3.4 & -73.5 & 130.9 \\
\hline 02031997 & 58.7 & 10.9 & -9.5 & 27.6 & 65.3 & -49.0 & 31.1 & -38.5 & 26.5 \\
\hline 04021999 & 49.3 & 10.9 & -9.6 & 38.1 & 30.2 & -30.0 & 11.2 & -55.3 & 59.5 \\
\hline 29111999 & 50.3 & 8.2 & -8.6 & 30.8 & 39.9 & -43.8 & 19.5 & -42.0 & 47.1 \\
\hline 15112004 & 48.1 & 8.9 & -8.1 & 36.5 & 30.8 & -35.7 & 11.6 & -59.4 & 77.9 \\
\hline 14092005 & 74.8 & 10.8 & -10.1 & 74.7 & 10.9 & -11.1 & 0.1 & -96.7 & 1028.8 \\
\hline 15112005 & 62.6 & 10.1 & -9.9 & 49.2 & 28.1 & -35.1 & 13.4 & -57.5 & 82.2 \\
\hline 12012009 & 58.0 & 10.5 & -8.4 & 35.3 & 57.0 & -43.9 & 22.7 & -64.0 & 48.4 \\
\hline Mean & 53.1 & 10.3 & -9.4 & 37.8 & 32.7 & -31.8 & 15.3 & -45.3 & 45.8 \\
\hline
\end{tabular}

The percentage change between the perturbed temperature $\left(+2\right.$ and $\left.-2{ }^{\circ} \mathrm{C}\right)$ simulations can be found in the $2 \mathrm{PL}$ and $2 \mathrm{NG}$ columns, respectively. All values are area averaged values for the west coast region (WC) seen in Fig. 2
Fig. 5 Relative (a) and absolute change (b) change in precipitation by comparing the PGWsimulation $2 \mathrm{PL}\left(+2{ }^{\circ} \mathrm{C}\right)$ with the control run (CTR) where the west coast region has been divided into height intervals and distance from the coast. The Coastal, Near Coastal and Inland regions are defined in Fig. 2. The different colors on the bars indicate the height intervals defined in the legend. The "All" bar contains all gridpoints within each of the $\mathrm{C}, \mathrm{NC}$ and I regions
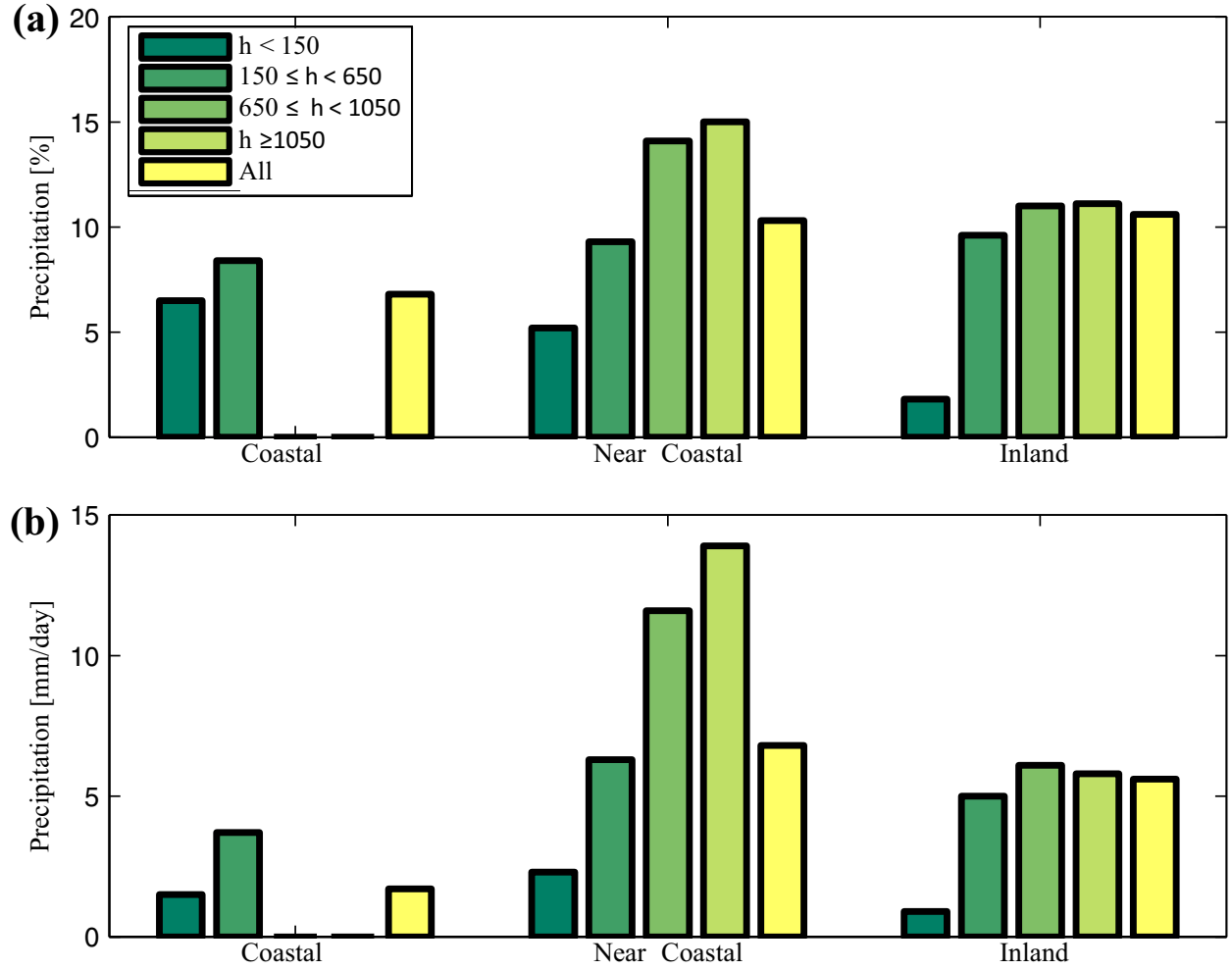

changes in total amounts are found in the high elevations of the near coastal area where the airflow hits the first major topographic barrier (Figs. 4c, 5). This area is also where the largest precipitation amounts are located in the control simulation. Simulations with decreased temperature (not shown) behaved slightly different for the inland area with the largest relative decrease for lower elevation areas (elevations lower than $650 \mathrm{~m}$ a.s.l.). As in the positive perturbation runs, the largest reduction in amounts occurred in the high elevation regions of the near coastal areas.

To get a better understanding of the microphysical changes with a warmer climate we divided the precipitation into liquid (rain) and solid (snow and graupel). In the warmer simulations, snowfall decreased by $\sim 22.7 \% / \mathrm{K}$ 

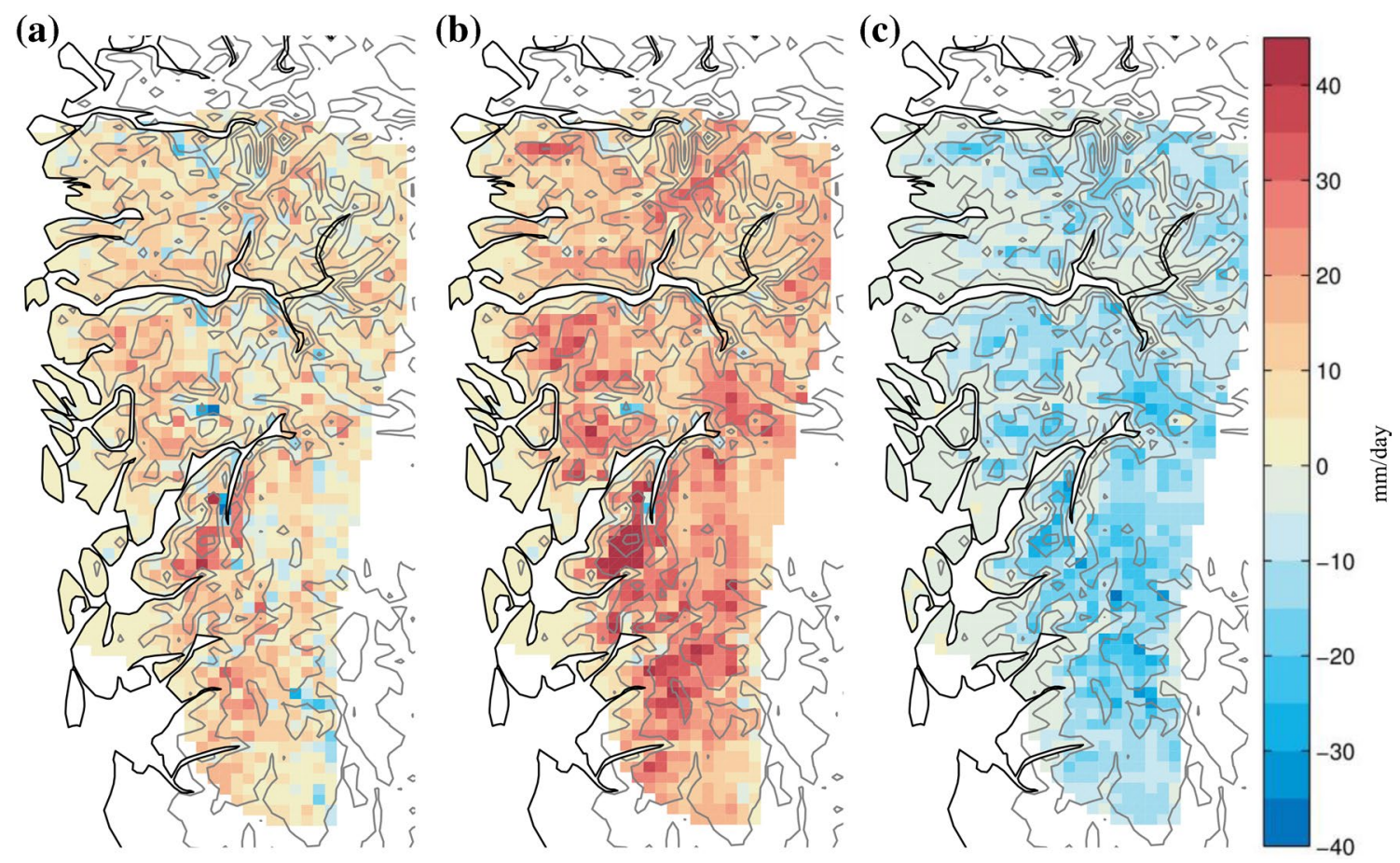

Fig. 6 Average absolute change ( $\mathrm{mm} /$ day) in precipitation (a), rainfall (b), and snowfall and graupel (c) between the $+2{ }^{\circ} \mathrm{C}$ perturbation simulations (2PL) and the control (CTR) for the 11 selected cases. The topography is indicated by the grey contours with a $200 \mathrm{~m}$ contour interval

(Fig. 6c; Table 4) while rainfall increased by $\sim 16.4 \% / \mathrm{K}$ (Fig. 6b; Table 4). This is due to the higher melting level, melting more of the solid precipitation to rain before hitting the ground. In terms of absolute values, the increase in daily rainfall was $12.4 \mathrm{~mm}$ while the reduction in snowfall and graupel was $6.9 \mathrm{~mm}$.

The simplest explanation of the increased precipitation is an increase of moisture associated with the $\mathrm{CC}$ relation. However, a change in precipitation efficiency could also lead to a change in precipitation amounts. Smith et al. (2003) found that precipitation efficiency can lead to artificially inflated condensation rates over multiple ridges. To evaluate how efficient Langfjella generates precipitation, the drying ratio (DR, the fraction of incoming water vapor flux that is rained out as air passes over the terrain) was examined. The advantage of this quantity is that it can take into account the multiple condensation and evaporation cycles over the complex terrain of southwest Norway. With an idealized cloud resolving model, Kirshbaum and Smith (2008) found a decrease in DR with an increase in temperature while RH was kept constant for a mountainous area. They argue that the main reason for this relationship is that the normalized (by incoming vapor flux) condensation rate decreases with increased temperature as dictated by the CC-relation, as well as a reduction in the precipitation efficiency due to a decrease in ice-phased precipitation growth. DR is defined as the ratio between the areal precipitation $(\mathrm{P})$ and the incoming water vapor flux (IWVF):

$D R=\frac{P}{I W V F}$

The DR is calculated for each of the 11 cases over the rectangular area shown in Fig. 1 covering the West Coast area (Table 5). The water vapor flux and accumulated precipitation are calculated over the $24 \mathrm{~h}$ period. The

Table 5 Drying ratio (DR, defined in Sect. 3.3.1) for the control run (CTR) and the two PGW simulations $2 \mathrm{PL}\left(+2^{\circ} \mathrm{C}\right)$ and $2 \mathrm{NG}\left(-2^{\circ} \mathrm{C}\right)$ for each of the 11 cases and the mean

\begin{tabular}{llll}
\hline $\begin{array}{l}\text { Date } \\
\text { ddmmyyyy }\end{array}$ & CTR & 2PL & 2NG \\
\hline 05031990 & 29.1 & 29.2 & 28.1 \\
11011992 & 21.5 & 20.6 & 22.5 \\
19101995 & 17.8 & 17.1 & 18.6 \\
27101995 & 20.1 & 20.0 & 20.6 \\
02031997 & 26.1 & 24.8 & 27.6 \\
04021999 & 19.6 & 18.6 & 20.8 \\
29111999 & 31.4 & 30.5 & 32.0 \\
15112004 & 21.9 & 20.8 & 23.1 \\
14092005 & 21.3 & 20.6 & 22.2 \\
15112005 & 31.2 & 31.9 & 29.9 \\
12012009 & 20.6 & 19.6 & 21.8 \\
Mean & 23.7 & 23.1 & 24.3 \\
\hline Units are \% & & &
\end{tabular}


Table 6 Column averaged hydrometeors (CTR columns) and relative changes $(\%)$ in column averaged hydrometeors for the $2 \mathrm{PL}\left(+2^{\circ} \mathrm{C}\right)$ and $2 \mathrm{NG}$ $\left(-2{ }^{\circ} \mathrm{C}\right)$ simulations in the atmosphere above the west coast region (see Fig. 2)

\begin{tabular}{|c|c|c|c|c|c|c|c|c|c|c|c|c|}
\hline \multirow{3}{*}{$\begin{array}{l}\text { Date } \\
\text { ddmmyyyy }\end{array}$} & \multicolumn{3}{|c|}{ Q_tot } & \multicolumn{3}{|c|}{ Cloud droplets } & \multicolumn{3}{|l|}{ Rain } & \multicolumn{3}{|c|}{ Snow + Ice + Graupel } \\
\hline & \multirow{2}{*}{$\begin{array}{l}\mathrm{g} / \mathrm{m}^{2} \\
\text { CTR }\end{array}$} & \multicolumn{2}{|l|}{$\%$} & \multirow{2}{*}{$\begin{array}{l}\mathrm{g} / \mathrm{m}^{2} \\
\text { CTR }\end{array}$} & \multicolumn{2}{|l|}{$\%$} & \multirow{2}{*}{$\begin{array}{l}\mathrm{g} / \mathrm{m}^{2} \\
\text { CTR }\end{array}$} & \multicolumn{2}{|l|}{$\%$} & \multirow{2}{*}{$\begin{array}{l}\mathrm{g} / \mathrm{m}^{2} \\
\text { CTR }\end{array}$} & \multicolumn{2}{|l|}{$\%$} \\
\hline & & 2PL & 2NG & & $2 \mathrm{PL}$ & $2 \mathrm{NG}$ & & $2 \mathrm{PL}$ & $2 \mathrm{NG}$ & & $2 \mathrm{PL}$ & $2 \mathrm{NG}$ \\
\hline 05031990 & 1.4 & 6.6 & -6.9 & 0.2 & 28.6 & -20.5 & 0.01 & 106.8 & -55.2 & 1.2 & 2.7 & -4.6 \\
\hline 11011992 & 1.9 & 2.7 & -4.6 & 0.4 & 37.0 & -29.6 & 0.1 & 111.9 & -62.0 & 1.5 & -9.4 & 3.5 \\
\hline 19101995 & 1.3 & 2.8 & -4.7 & 0.5 & 15.3 & -19.7 & 0.1 & 43.1 & -39.4 & 0.6 & -15.0 & 14.3 \\
\hline 27101995 & 1.7 & 15.1 & -6.8 & 0.3 & 26.1 & -22.0 & 0.1 & 57.1 & -42.7 & 1.2 & 8.4 & 0.5 \\
\hline 02031997 & 2.1 & 4.0 & -4.5 & 0.2 & 36.3 & -27.5 & 0.04 & 116.4 & -63.4 & 1.8 & -2.7 & -0.2 \\
\hline 04021999 & 1.8 & 3.6 & -3.1 & 0.7 & 15.0 & -14.6 & 0.1 & 34.9 & -28.5 & 0.9 & -9.8 & 9.4 \\
\hline 29111999 & 2.0 & 3.7 & -4.6 & 0.2 & 35.3 & -29.1 & 0.05 & 91.1 & -57.8 & 1.7 & -2.2 & -0.3 \\
\hline 15112004 & 2.6 & 11.4 & -9.6 & 0.6 & 19.2 & -20.9 & 0.3 & 31.2 & -30.1 & 1.7 & 5.1 & -1.9 \\
\hline 14092005 & 1.6 & 4.1 & -4.0 & 0.5 & 26.2 & -25.4 & 0.1 & 69.8 & -49.4 & 1.1 & -10.3 & 8.7 \\
\hline 15112005 & 2.0 & 2.7 & -2.9 & 0.4 & 33.3 & -28.1 & 0.1 & 80.1 & -53.1 & 1.5 & -11.5 & 7.8 \\
\hline 12012009 & 2.0 & 4.8 & -2.7 & 0.4 & 30.3 & -23.8 & 0.1 & 92.6 & -56.4 & 1.6 & -5.3 & 4.8 \\
\hline Mean & 1.9 & 5.6 & -4.9 & 0.4 & 27.5 & -23.7 & 0.1 & 75.9 & -48.9 & 1.3 & -4.5 & 3.8 \\
\hline
\end{tabular}

Q_tot is the sum of cloud droplets, rain, snow, ice and graupel. Values are column integrated. CTR gives us the average amount in $\mathrm{g} / \mathrm{m}^{2}$ for each of the 11 cases and the mean. 2PL and $2 \mathrm{NG}$ is the percentage change between the two PGW simulations, respectively, and the control runs flux is calculated by integrating the moisture transport horizontally, vertically (up to $15 \mathrm{~km}$ altitude) and in time for each side of the box separately using the wind direction perpendicular to the box side. The average DR for the CTR was $23.7 \pm 4.9 \%$ for the 11 cases. In a warmer climate the DR is reduced to $23.1 \pm 5.2 \%$, where two of the cases experienced a small increase in DR. Thus, by increasing the temperature the extreme cases in general experienced a slightly lower precipitation efficiency, consistent with the results found in Kirshbaum and Smith (2008). This slight reduction of only $0.5 \%$ suggest that the enhanced moisture effect on precipitation change dominated any change in precipitation efficiency.

The hydrometeor composition changes when the temperature increases (Table 6). The total hydrometeor mass changed by an average of $2.8 \pm 2.0 \% / K$. From Table 6 one can also see that the control simulation contains on average twice as much solid water as liquid water (as given by the cloud droplets column). In general, there is a reduction of $2.3 \pm 3.8 \% / \mathrm{K}$ in solid water hydrometeors in a warmer atmosphere. There is however an increase in solid hydrometeors in a warmer atmosphere for three of the eleven cases. A possible reason for this is that a warmer atmosphere has the capability to hold more vapor to condense. So at high altitudes where it is still cold enough for snow, there is more available vapor for ice phase growth process as long as RH has not decreased, which can be seen in Figs. 7 and 8 and discussed in Sect. 3.3.2.

Our extreme cases are a product of orographic enhanced precipitation with little formation of convection plumes. The average atmospheric lapse rate $(\Gamma=-d T / d z)$ over the WC region was $5.4 \mathrm{~K} / \mathrm{km}$ for the lowest $5 \mathrm{~km}$ and maximum gridsquare CAPE was in most cases lower than $1000 \mathrm{~J} / \mathrm{kg}$. Both the 2PL and 2NG simulations experience only small changes in the lapse rate (less than $0.1 \mathrm{~K} / \mathrm{km}$ changes) with the warmer environment becoming slightly more stable and average CAPE reduced by around $4 \%$. The area and column integrated (weighted with mass of water vapor) vertical velocity in the CTR was $6.2 \mathrm{~cm} / \mathrm{s}$ and increased by only $0.4 \pm 0.1 \mathrm{~cm} / \mathrm{s}$ (Table 7), similar to the results by Rasmussen et al. (2011) over the $\mathrm{CH}$. Thus, the areal average air column is ascending slightly faster with increased temperatures. The vertical velocity was also divided into updrafts and downdrafts. A larger part of the area was covered by updrafts compared to downdrafts for the CTR. The average velocity in the CTR was also higher for the updrafts with $30.1 \pm 5.8 \mathrm{~cm} / \mathrm{s}$ compared to $-23.9 \pm 5.8 \mathrm{~cm} / \mathrm{s}$ for the downdrafts. By increasing the temperature both the updrafts and downdrafts experienced a reduction in velocity of -1.3 and $-3.5 \%$, respectively, as well as a small increase and decrease of about $0.5 \%$ in the area covering the updrafts and downdrafts, respectively. When averaging the column integrated vertical velocity, the small increase of $0.4 \pm 0.1 \mathrm{~cm} / \mathrm{s}$ is a result of the stronger reduction in the velocity in the downdrafts compared to updrafts and a small increase in the area experiencing updrafts. Following the PGW method RH is not changed at the boundary conditions and the model results indicate only a small change in column integrated area mean $\mathrm{RH}$ when perturbing the temperature (Table 7). The area mean CTR RH was $90.2 \%$, with an average change of $0.5 \pm 0.1 \% / \mathrm{K}$ for the 2PL simulations. 


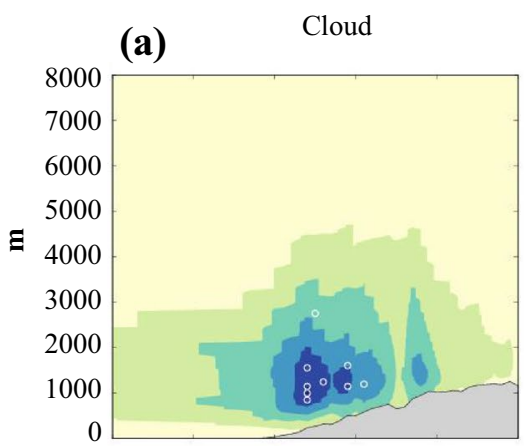

(d)

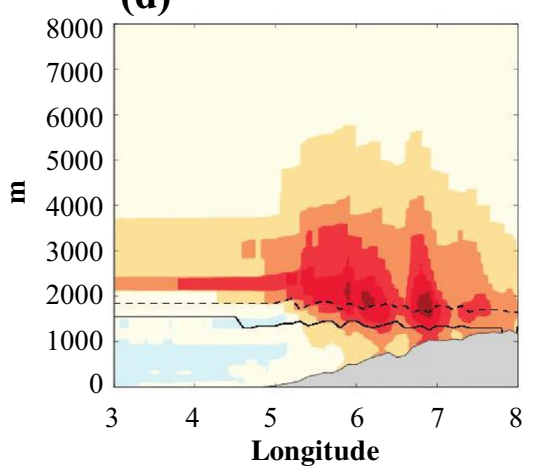

(b)

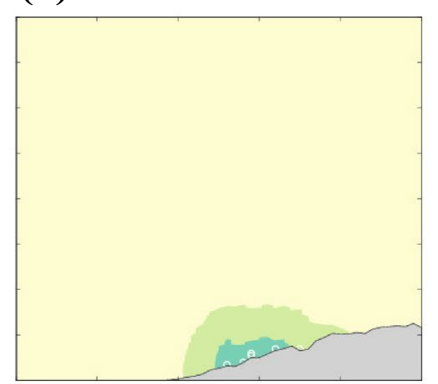

(e)

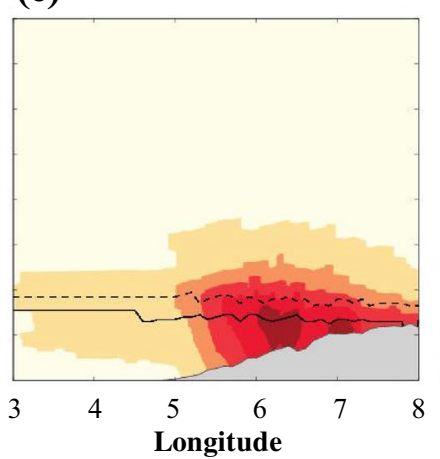

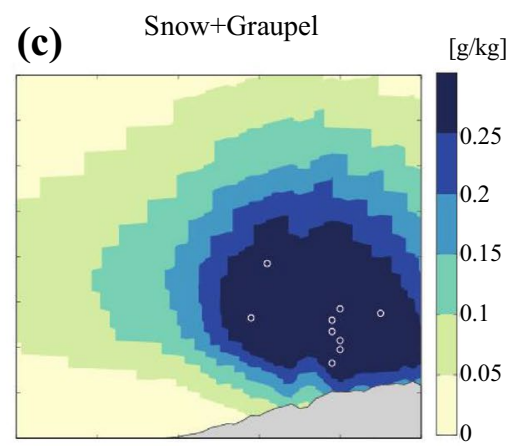

(f) $[\mathrm{g} / \mathrm{kg}]$

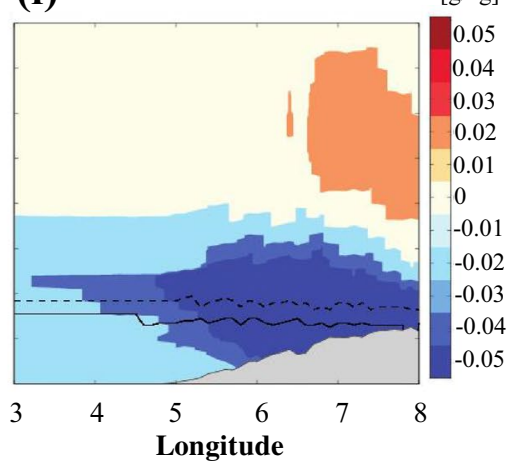

Fig. 7 The vertical transect of cloud droplets (a), rain (b) and snow + graupel (c) in $\mathrm{g} / \mathrm{kg}$ from the coast to the top of the Langfjella, averaged over the 11 cases and meridionally averaged over the box shown in Fig. 2. The white circles in the first row show the maximum values for each of the 11 cases to give an indication on the spread. d-f Absolute change in $\mathrm{g} / \mathrm{kg}$ between the $+2{ }^{\circ} \mathrm{C}$ perturbation simulations (2PL) and the control (CTR). The black solid and dashed line shows the mean zero isotherm for the CTR and the 2PL simulation, respectively

\subsubsection{Changes in the vertical structure}

By perturbing the temperature field, the height of the $0^{\circ} \mathrm{C}$ isotherm will be changed and this may affect the growth processes of hydrometeors. Snow and ice crystals have a lower saturation pressure than liquid droplets, and therefore grow more efficiently and often deplete the available moisture to ice saturation. For warm cloud processes, the precipitation growth is dominated by the collision-coalescence process. However, as shown in both Kirshbaum and Smith (2008) and Siler and Roe (2014) the increase in condensation rate is less than the increase in atmospheric water vapor. In other words, the air needs to be lifted further up to reach condensation. For our 11 cases the $0^{\circ} \mathrm{C}$ isotherm was elevated with approximately $200 \mathrm{~m} / \mathrm{K}$ (Fig. $7 \mathrm{~d}-\mathrm{f}$ ) which is similar to the shift found in Rasmussen et al. (2011).

To get a better representation of these changes, vertical cross-sections of the cloud water, rainwater and snow mixing ratio changes were analyzed (Fig. 7). Cloud water has a maximum between 500 and $2000 \mathrm{~m}$ a.s.l. with the highest values on the mountain chains closest to the coast (white circles in Fig. 7a). The rainwater maximum is at lower altitudes and slightly further inland compared to cloud water. This shift in maxima is expected due to

advection and the microphysical delay in production of rainwater. Maxima in snow and graupel on the other hand are mostly located in the inland area and at higher elevations (1500-4000 m a.s.l). By comparing liquid vs solid water amounts for the CTR run, there is a clear shift from mostly liquid cloud water in the lowest $2000 \mathrm{~m}$ for the coastal and near-coastal areas to mostly solid in the inland area. Warmer future temperatures result in a general increase in cloud water (Fig. 7d) with the largest increases associated with the strongest updrafts (Fig. 8b). For the area from the coast towards the west below $1000 \mathrm{~m}$ the cloud water experiences a small decrease with increasing temperatures. The same area shows a slight reduction in RH (Fig. 8c). Rainwater has increased with the large increase towards the ground between 6 and $7^{\circ}$ longitude (Fig. 7e). An interesting aspect of the hydrometeor changes with warming is the increase in RH (Fig. 8c) and snow amount (Fig. 7f) at altitudes above $4 \mathrm{~km}$ near the top of the Langfjella. This is similar to what was found in Rasmussen et al. (2011) for Colorado. Norwegian mountains are too low for the increase in snow to be as pronounced as in Rasmussen et al. (2011). The increase in cloud water underneath the snow could potentially explain some of the enhanced precipitation at 

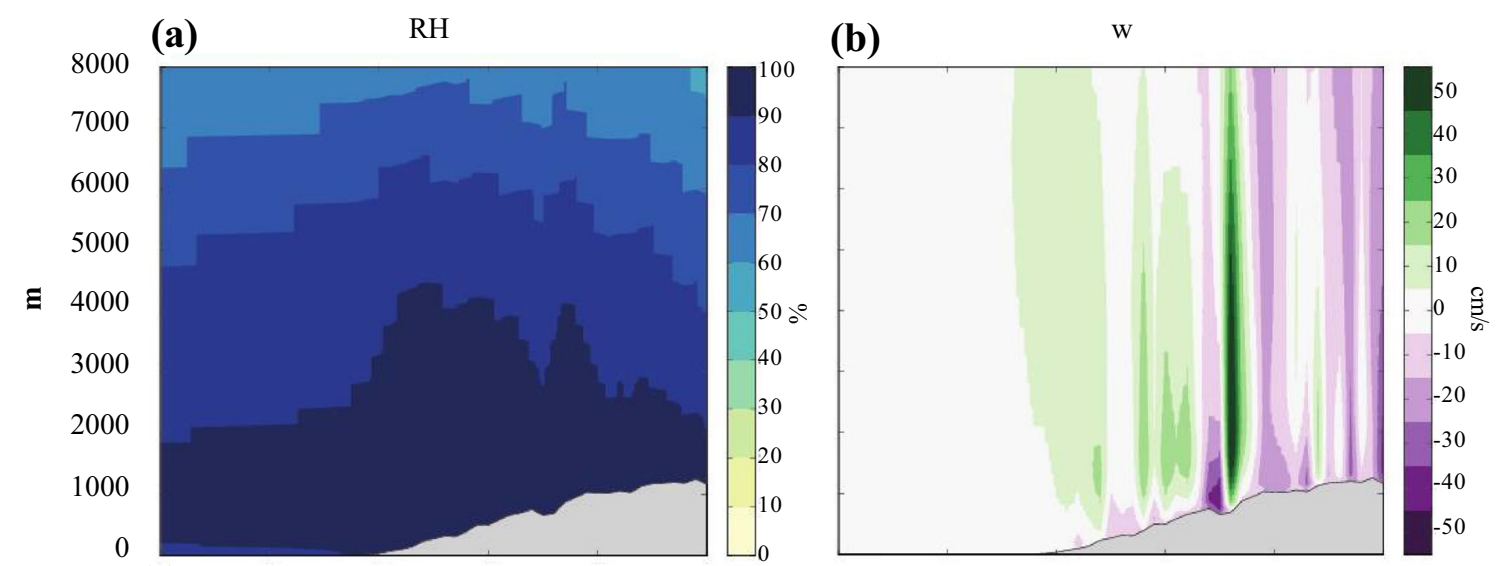

(c)

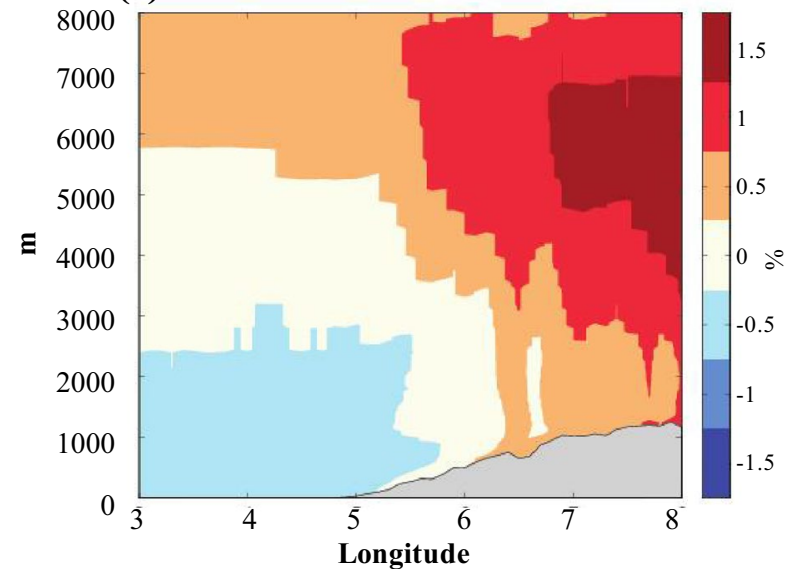

(d)

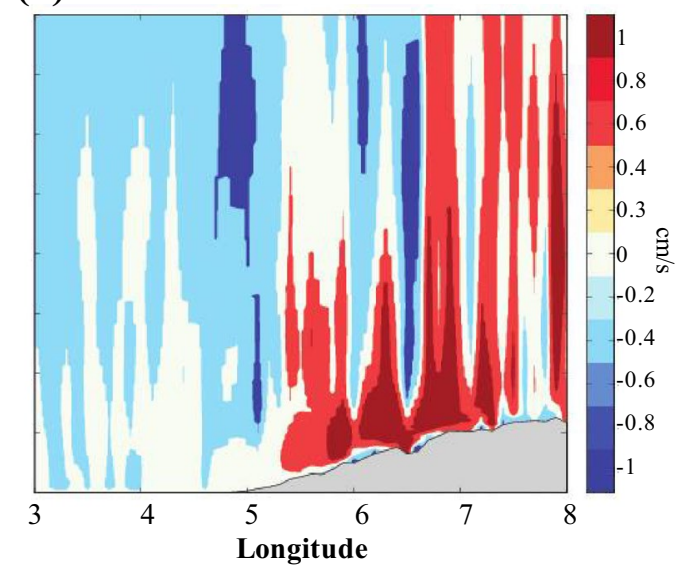

Fig. 8 The vertical transect of relative humidity (RH) in \% (a) and vertical velocity (w) in $\mathrm{cm} / \mathrm{s}$ (b) from the coast to the top of the Langfjella, averaged over the 11 cases and meridionally averaged over the

box shown in Fig. 2. c, $\mathbf{d}$ Change between the $+2{ }^{\circ} \mathrm{C}$ perturbation simulations (2PL) and the control (CTR) in RH (\%) and w $(\mathrm{cm} / \mathrm{s})$
Table 7 The change between the two PGW simulations $2 \mathrm{PL}$ $\left(+2{ }^{\circ} \mathrm{C}\right)$ and $2 \mathrm{NG}\left(-2^{\circ} \mathrm{C}\right)$ and the control run for each of the variables specific humidity $(\%)$, temperature $(\mathrm{K})$, relative humidity $(\Delta \mathrm{RH})$ and vertical velocity $(\mathrm{cm} / \mathrm{s})$ are listed for each of the 11 extreme events and the mean

\begin{tabular}{|c|c|c|c|c|c|c|c|c|c|c|c|}
\hline \multirow[t]{2}{*}{$\begin{array}{l}\text { Date } \\
\text { ddmmyyyy }\end{array}$} & \multicolumn{2}{|c|}{$\begin{array}{l}\text { Specific humid- } \\
\text { ity [\%] }\end{array}$} & \multicolumn{3}{|c|}{ Temperature $[\mathrm{K}]$} & \multicolumn{3}{|c|}{ Relative humidity [\%] } & \multicolumn{3}{|c|}{$\begin{array}{l}\text { Vertical velocity }[\mathrm{cm} / \\
\left.\mathrm{s}^{2}\right]\end{array}$} \\
\hline & 2PL & $2 \mathrm{NG}$ & CTR & $2 \mathrm{PL}$ & $2 \mathrm{NG}$ & CTR & $2 \mathrm{PL}$ & $2 \mathrm{NG}$ & CTR & 2PL & $2 \mathrm{NG}$ \\
\hline 05031990 & 15.9 & -14.1 & 261.9 & 1.8 & -1.9 & 87.1 & 0.3 & -0.5 & 9.4 & -0.04 & -0.2 \\
\hline 11011992 & 17.4 & -15.0 & 265.2 & 1.9 & -1.9 & 85.6 & 0.9 & -1.0 & 1.8 & 0.7 & -0.7 \\
\hline 19101995 & 16.0 & -14.1 & 268.4 & 2.0 & -2.0 & 86.8 & 0.1 & -0.2 & 4.7 & 0.01 & -0.4 \\
\hline 27101995 & 15.4 & -13.7 & 268.8 & 1.9 & -1.9 & 91.4 & 0.1 & -0.3 & 4.0 & 0.7 & -0.5 \\
\hline 02031997 & 16.7 & -14.5 & 263.9 & 1.9 & -1.9 & 92.1 & 0.7 & -0.7 & 9.5 & 0.4 & -0.4 \\
\hline 04021999 & 16.8 & -14.7 & 265.8 & 1.9 & -1.9 & 90.9 & 0.5 & -0.7 & 6.6 & 0.3 & -0.4 \\
\hline 29111999 & 15.4 & -13.8 & 264.8 & 1.8 & -1.8 & 90.1 & 0.4 & -0.6 & 6.9 & 0.2 & -0.2 \\
\hline 15112004 & 16.5 & -14.4 & 266.1 & 1.9 & -1.9 & 91.1 & 0.6 & -0.8 & 6.2 & 0.4 & -0.4 \\
\hline 14092005 & 15.3 & -13.7 & 272.1 & 1.9 & -1.9 & 95.2 & 0.5 & -0.8 & 5.6 & 1.0 & -0.8 \\
\hline 15112005 & 16.9 & -14.9 & 266.2 & 2.0 & -2.0 & 88.7 & 0.4 & -0.6 & 7.9 & 0.3 & -0.5 \\
\hline 12012009 & 16.7 & -14.5 & 266.6 & 1.9 & -1.9 & 92.7 & 0.7 & -0.8 & 5.8 & 0.5 & -0.4 \\
\hline Mean & 16.2 & -14.3 & 266.3 & 1.9 & -1.9 & 90.2 & 0.5 & -0.6 & 6.2 & 0.4 & -0.4 \\
\hline
\end{tabular}

CTR run values for all of the 11 cases are also included for the variables temperature $(\mathrm{K})$, relative humidity $(\%)$ and vertical velocity $\left(\mathrm{cm} / \mathrm{s}^{2}\right)$. All values are column averages weighed by the mass of the moisture in each model layer (see Sect. 3.3 for details) as well as area averaged over the west coast (WC) region (Fig. 2) 
Table 8 Average fraction of accumulated precipitation, rain, and snow and graupel that falls out on the west coast region compared to the total amount that falls out on both the western and eastern side of Langfjella for the 11 cases

\begin{tabular}{llll}
\hline & Precipitation & Rain & $\begin{array}{l}\text { Snow } \\
\text { and } \\
\text { Graupel }\end{array}$ \\
\hline CTR & 0.873 & 0.918 & 0.778 \\
2PL & 0.870 & 0.895 & 0.745 \\
2NG & 0.877 & 0.944 & 0.811 \\
\hline
\end{tabular}

high terrain due to enhanced precipitation growth by the "seeder-feeder" mechanism for snow.

There are clearly updrafts and downdrafts of air as the weather system forces the air over Langfjella (Fig. 8b). A similar pattern is present for each of the 11 cases (not shown). By increasing the temperature, both positive and negative changes are apparent (Fig. 8d), the maximum change is less than $2 \%$ compared to the maximum CTR value. There is a mix of increasing and decreasing upward as well as downward motion when comparing Fig. 8b, d. The changes are similar for the vertical velocity for all the extreme events evaluated (not shown). These weak changes in the vertical velocity support the previous findings that they do not play a significant role in the precipitation response.

\subsubsection{Shifts in precipitation pattern over the mountain range}

Fractions of precipitation between the West Coast (WC) and the West Coast together with Southern Norway (SN), which is east of the mountains (Fig. 2), are used to investigate if there has been a significant change in how much of the total precipitation that is falling on the western windward side of the Langfjella:

$f_{\text {west }}=\frac{\sum x_{W C}}{\sum\left(x_{W C}+x_{S N}\right)}$

where $\mathrm{x}$ represents either precipitation, rain, and snow and hail. Changes in this fraction are an indication of changes in the amount of condensation in the different regions, the microphysical production timescale, fall velocities and advection. The fraction of accumulated precipitation on the western (windward) side of the mountain range Langfjella compared to the eastern (lee) side did not change much with temperature (less than $-0.5 \% / \mathrm{K}$, Table 8 ). As stated in Sect. 3.3.1 the daily precipitation had a response of around $5 \% / \mathrm{K}$ compared with around $8 \% / \mathrm{K}$ for the specific humidity for the WC area. This indicates a change in the influx of water to the lee side which is larger than CC scaling. The small increase of daily precipitation on the lee side of the mountain may be a result of the increased amount of water vapor crossing the mountain range. However, this is outside the region experiencing extreme precipitation and will not be investigated in more detail.

\section{Summary and concluding remarks}

In this study we have examined the sensitivity of historical extreme precipitation events over the west coast of Norway are to an idealized change in the atmospheric temperature. We simulated 11 extreme precipitation events that occurred between 1990 and 2011, using a pseudo global warming method (Schär et al. 1996). This idealized setup involved first simulating the 11 cases with boundary conditions from the ERA-Interim reanalysis; called the control run (CTR), followed by two sets of perturbed simulations; the 2PL and $2 \mathrm{NG}$, where all the temperature fields were changed by +2 and $-2{ }^{\circ} \mathrm{C}$, respectively. This method allows us to isolate the effects of changes in the thermodynamics, i.e. increased temperature, moisture content and small scale dynamics while keeping the large and synoptic-scale dynamical structure similar. Relative humidity was kept constant, resulting in a change in the specific humidity over the west coast (WC) region of $8.1 \% / \mathrm{K}$ for the PGW simulations $2 \mathrm{PL}$ compared to the control run CTR.

WRF was able to replicate the observed precipitation pattern with the lowest accumulation along the coast, highest accumulation along the first major slope in the topography, and relatively high amounts further inland. On average, WRF underestimated the accumulated daily precipitation by $5.6 \%$ for the 11 extremes and has a MAE of $22.2 \mathrm{~mm} / \mathrm{day}$. There is a tendency for WRF to underestimate precipitation in the coastal and near coastal areas and overestimate the precipitation further inland. A correction for undercatch of the snow gauge observations might have altered some of the verification results but were not done due to lack of wind and temperature measurements at the precipitation station locations.

The daily precipitation had an average change of $\sim 5 \% / \mathrm{K}$ for the WC region, which is less than that given by the CC-relation $(\sim 7 \% / \mathrm{K})$ and the change in specific humidity $(\sim 8 \% / \mathrm{K})$. The change was however not uniform through the region. Areas located at elevations higher than $650 \mathrm{~m}$ a.s.l. experienced the largest change, $\sim 6.4 \% / \mathrm{K}$, peaking at $7.5 \% / \mathrm{K}$ for the highest elevations in the near coastal mountain regions, while the lowest changes were located at elevations lower than $150 \mathrm{~m}$ a.s.l with a change of $\sim 2.3 \% / \mathrm{K}$. In other words, there is in general a larger percentage increase in daily precipitation in terrain located at higher altitudes. This may be due to the dependence of the larger fractional change in condensation at lower temperatures 
or possibly an increase in the seeder-feeder mechanism as more cloud water is present underneath the snow crystals in the 2PL simulation. The largest changes in absolute as well as relative accumulated precipitation in the control runs were located where the airflow is forced over the first major topographic slope of the near coastal mountains.

Changes in variables such as vertical velocity, relative humidity and the stability were relatively modest and could not explain the below CC scaling response in precipitation. The likely cause for the lower response in precipitation compared to what is expected from the CC-relation is a change of microphysical growth processes due to a warmer in-cloud temperature. This affects the composition and growth of different hydrometeors in the atmosphere. A warmer atmosphere will be less favorable for the production and growth of snow, graupel and ice, and more favorable for rain. Production of snowfall and graupel had a mean reduction of around $23 \% / \mathrm{K}$, while the rainfall amounts increased with about $16 \% / \mathrm{K}$. As snow and ice crystals grow at a lower saturation pressure compared to liquid droplets (Wallace and Hobbs 2006), this makes them grow efficiently. The atmosphere compensates for this, however, by causing cloud droplets to auto-convert to drizzle and rain through the higher cloud mixing ratio reached in the warmer cloud. The combined effect of increased coalescence rain and snow melting is apparently insufficient to compensate for the reduced snow and graupel growth (16\% increase versus $24 \%$ decrease). As a result, the precipitation increases at a rate slightly below the $\mathrm{CC}$ rate, but still a $5 \% / \mathrm{K}$, leading to significantly more extreme precipitation in a warmer climate. Rasmussen et al. (2011) found an increase in snowfall over the Colorado Headwaters in a warmer atmosphere due to enhanced riming growth. We see a similar increase in snow at altitudes above $4 \mathrm{~km}$ (2.5 $\mathrm{km}$ above the topography) near the top of Langfjella (Fig. 7f), but due to the fact that the Norwegian mountains are much lower and the lower troposphere is warmer the enhanced snow mass was much less pronounced than in Rasmussen et al. (2011) and could not compensate for the reduction in snow production at lower altitudes.

To what extent our idealized simulations are close to the results of full RCM simulations is beyond the scope of this paper. But we note that the national report Klima 2100 (Hanssen-Bauer et al. 2015) reports wintertime precipitation changes on the west coast of $\sim 16 \%$ with a $3{ }^{\circ} \mathrm{C}$ warming for the rcp8.5 scenario.

Acknowledgements The authors acknowledge NCAR Research Applications Laboratory staff and the Water System scientists for providing a productive research environment and the computer time to conduct the high-resolution simulations on the Yellowstone computer cluster. The authors are especially grateful to Changhai Liu for all the help with the setup of the model simulations. The work was partly funded by the Bjerknes Centre for Climate Research, University of
Bergen and the Norwegian Research Council project ExPrecFlood. For useful and informative discussions, the authors acknowledge Silje Lund Sørland.

Open Access This article is distributed under the terms of the Creative Commons Attribution 4.0 International License (http:// creativecommons.org/licenses/by/4.0/), which permits unrestricted use, distribution, and reproduction in any medium, provided you give appropriate credit to the original author(s) and the source, provide a link to the Creative Commons license, and indicate if changes were made.

\section{References}

Allan MR, Ingram WJ (2002) Constraints on future changes in climate and the hydrologic cycle. Nature 419:224-232. doi:10.1038/ nature 01092

Bengtsson L, Hodges K, Roeckner E (2006) Storm tracks and climate change. J Clim 19:3518-3543

Bengtsson L, Hodges K, Keenlyside N (2009) Will extratropical storms intensify in a warmer climate? J Clim 22:2276-2301

Bony S, Duvel LP, Treut, HL (1995) Observed dependence of the water vapor and clear-sky greenhouse effect on sea surface temperature: comparison with climate warming experiments. Clim Dynam 11:307-320

Collins M, Knutti R, Arblaster J, Dufresne JL, Fichefet T, Friedlingstein P, Gao X, Gutowski WJ, Johns T, Krinner G, Shongwe M, Tebaldi C, Weaver AJ, Wehner M (2013) Long-term climate change: projections, commitments and irreversibility. In: Climate Change 2013: The Physical Science Basis. Contribution of Working Group I to the Fifth Assessment Report of the Intergovernmental Panel on Climate Change. Cambridge University Press, Cambridge

Dee DP, Uppala SM, Simmons AJ, Berrisford P, Poli P, Kobayashi $S$ et al (2011) The era-interim reanalysis: configuration and performance of the data assimilation system. Q J Roy Meteorol Soc 137:553-597

Frei C, Schär C, Lüthi D, Davis HC (1998) Heavy precipitation processes in a warmer climate. Geophys Res Lett 25:1431-1434

Hanssen-Bauer I, Førland EJ (1998) Annual and seasonal precipitation variations in Norway 1896-1997. Klima-Report 27/98, Norwegian Meteorological Institute

Hanssen-Bauer I, Drange H, Førland EJ, Roald LA, Børsheim KY, Hisdal H, Lawrence D, Nesje A, Sandven S, Sorteberg A, Sundby S, Vasskog K, Ådlandsvik B (2009) Klima i Norge 2100. Background material to NOU Klimatilpasning, Norsk klimasenter, September 2009, Oslo

Hanssen-Bauer I, Førland EJ, Haddeland I, Hisdal H, Mayer S, Nesje A, Nilsen JEØ, Sandven S, Sandbø AB, Sorteberg A, Ådlandsvik B (2015) Klima i Norge 2100. Background material to Klimatilpasningm Norsk Klimasevicesenter (NKSS), September 2015, Oslo

Heikkilä U, Sorteberg A (2012) Characteristics of autumn-winter extreme precipitation on the Norwegian west coast identified by cluster analysis. Clim Dynam 39:929-939. doi:10.1007/ s00382-011-1277-9

Heikkilä U, Sandvik A, Sorteberg A (2011) Dynamical downscaling of era-40 in complex terrain using the WRF regional climate model. Clim Dynam 37:1551-1564. doi:10.1007/ s00382-010-0928-6

Im ES, Coppola E, Giorgi F, Bi X (2009) Local effects of climate change over the Alpine region: a study with a high resolution 
regional climate model with a surrogate climate change scenario. Geophys Res Lett 37:L05704. doi:10.1029/2009GL041901

Kirshbaum DJ, Smith RB (2008) Temperature and moist-stability effects on midlatitude orographic precipitation. Q J Roy Meteorol Soc 134:1183-1199. doi:10.1002/qj.274

Kröner N, Kotlarski S, Fischer E, Lüthi D, Zubler E, Schär C (2016) Separating climate change signals into thermodynamic, lapse-rate and circulation effects: theory and application to the European summer climate. Clim Dynam. doi:10.1007/ s00382-016-3276-3

Laîné A, Kageyama M, Salas-Mélia D, Ramstein G, Planton S, Denvil S, Tyteca S (2009) An energetics study of wintertime Northern Hemisphere storm tracks under $4 \mathrm{xCO}_{2}$ conditions in two ocean-atmosphere coupled models. J Clim 22:819-839. doi:10. 1175/2008JCLI2217.1

Liu C, Ikeda K, Rasmussen R, Barlage M, Newman AJ, Prein AF, Chen F, Chen L, Clark M et al (2016) Continental-scale convection-permitting modeling of the current and future climate of North America. Clim Dynam. doi:10.1007/s00382-016-3327-9

Loriaux JK, Lenderink G, De Roode SR, Siebesma AP (2013) Understanding convective extreme precipitation scaling using observations and an entraining plume model. J Atmos Sci 70:3641-3655

Muller C, O'Gorman PA (2011) Intensification of precipitation extremes with warming in a cloud-resolving model. J Clim 24:2784-2800. doi:10.1175/2011JCLI3876.1

O'Gorman PA, Muller C (2010) How closely do changes in surface and column water vapor follow Clausius-Clapeyron scaling in climate change simulations? Environ Res Lett 5:025207. doi:10.1088/1748-9326/5/2/025207

O'Gorman PA, Schneider T (2009a) Scaling of precipitation extremes over a wide range of climates simulated with an idealized GCM. J Clim 22:5676-5685

O'Gorman PA, Schneider T (2009b) The physical basis for increases in precipitation extremes in simulations of 21 st-century climate change. Proc Natl Acad Sci 106:14773-14777. doi:10.1073/ pnas.0907610106

Pall P, Allen M, Stone D (2006) Testing the clausius-clapeyron constraint on changes in extreme precipitation under $\mathrm{CO}_{2}$ warming. Clim Dynam 28:351-363

Rasmussen R, Liu C, Ikeda K, Gochis D, Yates D, Chen F, Tewari M, Barlage M, Dudhia J, Yu Wei, Miller K (2011) High-resolution coupled climate runoff simulations of seasonal snowfall over Colorado: A process study of current and warmer climate. J Clim 24:3015-3048

Rasmussen R, Baker B, Kochendorfer J, Meyers T, Landolt S, Fischer AP, Black J, Thériault JM, Kucera P, Gochis D, Smith C, Nitu R, Hall M, Ikeda K, Gutmann E (2012) How well are we measuring snow: the NOAA/FAA/NCAR winter precipitation test bed. B Am Meteorol Soc 93:811-829. doi:10.1175/ BAMS-D-11-00052.1

Schär C, Frei C, Lüthi D, Davis HC (1996) Surrogate climate change scenarios for regional climate models. Geophys Res Lett 23:669-672

Siler N, Roe G (2014) How will orographic precipitation respond to surface warming? An idealized thermodynamic perspective. Geophys Res Lett 41:2606-2613. doi:10.1002/2013GL059095

Singh MS, O'Gorman PA (2014) Influence of microphysics on the scaling of precipitation extremes with temperature. Geophys Res Lett 41:6037-6044. doi:10.1002/2014GL061222

Skamarock WC, Klemp JB, Dudhia J, Gill DO, Barker DM, Wang W et al (2008) A description of the advanced research wrf version 3. NCAR Tech Note NCAR/TN-475 + STR, p 88

Smith RB, Jiang Q, Fearon MG, Tabary P, Dorninger M, Doyle JD, Benoit R (2003) Orographic precipitation and air mass transformation: an Alpine example. Q J Roy Meteorol Soc 129:433-454. doi:10.1256/qj.01.212

Sørland S, Sorteberg A, Liu C, Rasmussen R (2016) Precipitation response of monsoon low-pressure systems to an idealized uniform temperature increase. J Geophys Res 121:6258-6272. doi:1 $0.1002 / 2015 J D 024658$

Sorteberg A, Walsh J, (2008) Seasonal cyclone variability at $70 \mathrm{~N}$ and its impact on moisture transport into the Arctic. Tellus A 60:570-586. doi:10.1111/j.1600-0870.2008.00314.x

Sugiyama M, Shiogama H, Emori S (2010) Precipitation extreme changes exceeding moisture content increases in MIROC and IPCC climate models. Proc Natl Acad Sci 107:571-575. doi:10.1073/pnas.0903186107

Trenberth KE, Dai A, Rasmussen R, Parsons DB (2003) The changing character of precipitation. B Am Meteorol Soc 84:1205

Ulbrich U, Pinto JG, Kupfer H, Leckebusch GC, Spangehl T, Reyers M (2008) Changing Nothern Hemisphere storm tracks in an ensemble of IPCC climate change simulations. J Clim 21:16691679. doi:10.1175/2007JCLI1992.1

Wallace JM, Hobbs PV (2006) Atmospheric science: an introductory survey, 2nd edn. vol 92. Academic Press, London, pp 80-82

Wolff MA, Isaksen K, Petersen-Øverleir A, Ødemark K, Reitan T, Brækkan R (2015) Derivation of a new continuous adjustment function for correcting wind-induced loss of solid precipitation: results of a Norwegian field study. Hydrol Earth Syst Sci 19:951-967. doi:10.5194/hess-19-951-2015

Yin JH (2005) A consistent poleward shift of the storm tracks in simulations of 21st century climate. Geophys Res Lett 32:L18701. doi:10.1029/2005GL023684 